\title{
Food Dyes are Inhibitors of Human Protein Tyrosine Phosphatases (PTP1B) Molecular Docking Studies
}

\author{
Ismail DAOUD \\ Laboratory of Naturals \\ Products and Bio \\ actives-LASNABIO. \\ Faculty of Sciences - \\ Department of \\ Chemistry. University \\ of Tlemcen- BP 119, \\ 13000. Algeria,
}

\author{
Mourad MESMOUDI \\ Laboratory of Naturals \\ Products and Bio \\ actives-LASNABIO. \\ Faculty of Sciences - \\ Department of \\ Chemistry. University of \\ Tlemcen- BP 119, \\ 13000. Algeria
}

\author{
Said GHALEM \\ Laboratory of Naturals \\ Products and Bio \\ actives-LASNABIO. \\ Faculty of Sciences - \\ Department of \\ Chemistry. University \\ of Tlemcen- BP 119, \\ 13000.Algeria
}

\begin{abstract}
Protein Tyrosine Phosphatase 1B (PTP1B) is an enzyme that plays a critical role in down-regulating insulin signaling through dephosphorylation of the insulin receptor. Inhibitors of PTP1B showed increased insulin sensitivity and normalize plasma glucose level and thus are use full therapeutic agents for the treatment of diabetes. The aim of the current study is to identify PTP1B inhibitors by means of virtual screening with docking. Six food dyes molecules have been screened and based on energy MolDok scores and hydrogen bonding interactions. $\mathbf{L}_{\mathbf{5}}, \mathbf{L}_{\mathbf{1}}$ potential inhibitors were identified in cavity1 and 2 respectively.
\end{abstract}

\section{Keywords}

Diabetes, PTP1B, Food dyes, Interactions, Molecular Docking.

\section{INTRODUCTION}

The activities and functions of cellular proteins are often regulated by posttranslational modifications. Tyrosine phosphorylation is an example of those modifications and the reversible nature of the phosphorylation provides the basis for the communication between the signaling proteins inside cell [1-4]. The phosphorylation state of a protein is dynamically controlled by the action of protein tyrosine kinases (PTKs) and protein tyrosine phosphatases (PTPases); PTKs catalyze the tyrosine phosphorylation and PTPases catalyze the reverse reaction $[5,6]$.

PTKases were discovered in 1980 [7] and later found to be extremely important for the regulation of cell transformation, growth, differentiation, apoptosis, and hormone actions. On the other hand, Protein tyrosine phosphatases (PTPs) constitute a large family of signaling enzymes. Deregulation of PTP activity can play a role in a number of diseases including diabetes, cancer, and dysfunction of the immune system. Fischer et al. purified and characterized the first PTPase, PTP-1B from the human placenta in 1988 [8,9]. PTP1B dephosphorylates the insulin receptor and causes resistance to insulin. Thus, it has been implicated in the development of type II diabetes [10]. Based on the structural similarity between it and leukocyte antigen CD45, they found that this antigen had PTPase activity [11]. Subsequently, more than 30 PTPases were cloned and reported [12]. PTPases form a large family of enzymes that can be divided into cytosolic types, such as $\mathrm{SH} 2$-domain-containing phosphotyrosine phosphatase (SHP2) and PTP-1B, and transmembrane types, such as CD45, receptor PTPase-a (RPTP-a), and leukocyte antigen related tyrosine phosphatase
(LAR). In the other hand, Synthetic colorants are a very important class of food additives. They are widely used to compensate for the loss of natural colors of food and the way to improve the esthetic quality of a food product, which is destroyed during processing and storage, and to provide the desired colored appearance. The total world colorant production is estimated to be $80,00,000$ tons per year [13]. However, some of these substances pose a potential risk to human health, especially if they are excessively consumed. For this reason, safety data, such as the acceptable daily intake, based on toxicological studies on experimental animals and human clinical studies, have been repeatedly determined and evaluated by Food and Agricultural Organization (FAO) and World Health Organization (WHO) [14]. They are divided into five major colorant classes: the azo compounds (such as amaranth and tartrazine...), the chinophthalon derivatives of Quinoline Yellow, the triarylmethane group, xanthenes (such as erythrosine) and the indigo colorants [15].

While studying the enzymology of protein tyrosine phosphatases (PTPases), they observed that some of the dyes behaved as potent inhibitors of PTPases [16,17]. PTPases are a class of enzymes that hydrolyze the phosphate moiety from a phosphotyrosine residue of a protein thus regulating the cellular phosphorylation level of proteins in collaboration with protein tyrosine kinases $[1,18]$. Because PTPases play important roles as regulators of a diverse of signal transduction pathways, inhibition of PTPases by food colorants might disturb a certain signaling pathways resulting in adverse effects in human health. The dye attracted our attention because it is a competitive inhibitor of PTPases and also it contains free hydroxyl groups to introduce additional structural features without a significant change of the core structure. In present paper molecular modeling studies were performed to study the structural features of the inhibitor binding to PTP1B.

\section{MATERIALS AND METHODS}

$\mathrm{X}$-ray crystallographic study has performed to explain the enzyme-inhibitor interactions with PTP1B and some food dyes. This work showed that PTP1B has two possible modes of inhibition depending on the structures of the ligands. Based on this result, molecular modeling was carried out to study the structural features of the interaction between PTP1B and food dyes.

\subsection{Ligands Structures}

Six food dyes was taken as ligands (Figure 1). These compounds were reported to bind with PTP1B and 
subsequently disturb a certain signaling pathways resulting in adverse effects in human health [19]. Therefore those were<smiles>O=C(O)c1ccccc1-c1c2cc(I)c(=O)c(I)c-2oc2c(I)c(O)c(I)cc12</smiles>

$\mathbf{L}_{1}$<smiles>COc1cc(S(=O)(=O)O)c(C)cc1N=Nc1c(O)ccc2cc(S(=O)(=O)O)ccc12</smiles>

$\mathbf{L}_{3}$<smiles>O=C(O)c1nn(-c2ccc(S(=O)(=O)O)cc2)c(O)c1/N=N/c1ccc(S(=O)(=O)O)cc1</smiles>

$\mathbf{L}_{5}$ also subjected to docking to examine their binding modes.<smiles>O=C(O)c1c(Cl)c(Cl)c(Cl)c(Cl)c1-c1c2cc(Br)c(=O)c(Br)c-2oc2c(Br)c(O)c(Br)cc12</smiles>

$\mathbf{L}_{2}$

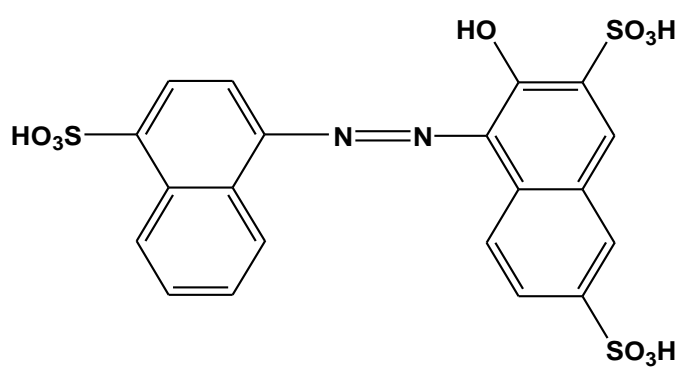

$\mathbf{L}_{4}$

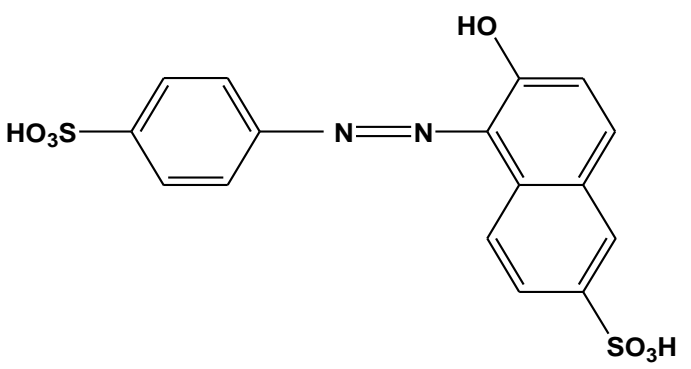

$\mathbf{L}_{6}$

Fig1: Chemical structure of the food dyes used. $L_{1}$ : Erythrosine $B, L_{2}$ : Phloxine B, $L_{3}$ : Allura Red AC, $L_{4}$ : Amaranth, $L_{5}$ : Tartrazine $\mathrm{L}_{6}$ : Sunset Yellow FCF

The full geometrical optimization of the food dyes L1-6 (Figure 1) in the gas phase were carried out at the level of semi-empirical AM1 method [20], as well as density functional theory (DFT) [21] using a gradient technique $[22,23]$ and $6-31 G^{*}[24,25]$ basis set. The DFT calculations were carried out with the B3LYP functional, in which Becke's nonlocal exchange $[26,27]$ and the Lee-Yang-Parr correlation functional [28] semi-empirical and DFT calculations were performed using GAUSSIAN 03 for Windows program package [29]. All calculations were done on a Pentium IV PC computer.
Table 1. Shows energies of each ligands used DFT/ B3LYP (6-31G*)

\begin{tabular}{|c|c|}
\hline ligands & Energies (u.a) \\
\hline $\mathbf{L}_{\mathbf{1}}$ & $\mathrm{HF}=-0.0074$ \\
\hline $\mathbf{L}_{\mathbf{2}}$ & $\mathrm{HF}=-0.1020$ \\
\hline $\mathbf{L}_{\mathbf{3}}$ & $\mathrm{HF}=-0.3203$ \\
\hline $\mathbf{L}_{\mathbf{4}}$ & $\mathrm{HF}=-0.4099$ \\
\hline $\mathbf{L}_{\mathbf{5}}$ & $\mathrm{HF}=-0.2881$ \\
\hline $\mathbf{L}_{\mathbf{6}}$ & $\mathrm{HF}=-0.2635$ \\
\hline
\end{tabular}


As shown in Table 2, broad spectrum of $\mathrm{IC}_{50}$ values was observed in food dyes ( $\left.\mathbf{L}_{\mathbf{1 - 6}}\right)$ [19].

Table 2. Inhibition of PTP1B by various synthetic dyes. Compounds $\mathrm{L}_{1-6}$

\begin{tabular}{|c|c|}
\hline Compounds & $\mathbf{I C}_{\mathbf{5 0}}(\boldsymbol{\mu M})^{\mathbf{a}}$ \\
\hline $\mathbf{L}_{\mathbf{1}}$ & $6.0 \pm 0.6$ \\
\hline $\mathbf{L}_{\mathbf{2}}$ & $4.2 \pm 0.3$ \\
\hline $\mathbf{L}_{\mathbf{3}}$ & $33 \pm 6$ \\
\hline $\mathbf{L}_{\mathbf{4}}$ & $34 \pm 7$ \\
\hline $\mathbf{L}_{\mathbf{5}}$ & $>190$ \\
\hline $\mathbf{L}_{\mathbf{6}}$ & $>220$ \\
\hline
\end{tabular}

${ }^{\mathrm{a}} \mathrm{IC}_{50}$ values were usually derived from duplicates or more of experiments using a range of inhibitor concentrations. The numbers indicate mean value \pm standard deviation

\subsection{Enzyme Structure}

The X-ray crystal structures of PTP1B bound with 6(difluoro-phosphono-methyl)-naphthalene- 2-carboxylic acid (1BZJ) [30], were downloaded from RCSB Database (www.rcsb.org/pdb) [31].

\subsection{The Simulation Details}

The structure of the protein was corrected for missing atoms or unknown units using Molegro Virtual Docker (MVD2011) [32-34] program, graphical-automatic software (http://molegro.com/mvd-product.php). 1BZJ has a monomer structure. So to simplify the simulation water was removed.
To locate the appropriate binding orientations and conformations of ligands on PTP1B, docking was performed by using Molegro Virtual Docker (MVD) software package. The identification of ligand binding modes is done by iteratively evaluating a number of candidate solutions (ligand conformations) and estimating the energy of their interactions with the macromolecule. MVD performs flexible ligand docking, so the optimal geometry of the ligand will be determined during the docking. The MolDock [35] scoring function (MolDock Score) used by MVD is derived from the PLP scoring functions originally proposed by Gehlhaar et al. and later extended by Yang et al. [36]. The MolDock scoring function further improves these scoring functions with a new hydrogen bonding term and new charge schemes.

\subsection{The Docking}

To obtain better potential binding sites in the PTP1B (PDB ID: 1BZJ), a maximum of five cavities was detected using default parameters. The volume of cavity $2\left(48.128 \mathrm{~A}^{3}\right)$ was found to be highest than the other cavities, also we found that the reference ligand of 1BZJ is fixed in cavity $1\left(41.472 \mathrm{~A}^{3}\right)$. Out of the detected cavities, cavity 1 and 2 was selected for further studies (figure 2). The chosen cavity was further refined using side chain minimization by selection of an addvisible option set at a maximum of 10,000 steps per residue and at a maximum of 10,000 global steps. The grid resolution was $0.30 \AA$; the max iterations were 1,500 ; the $\max$ population size was 50 and the energy threshold was 100 .

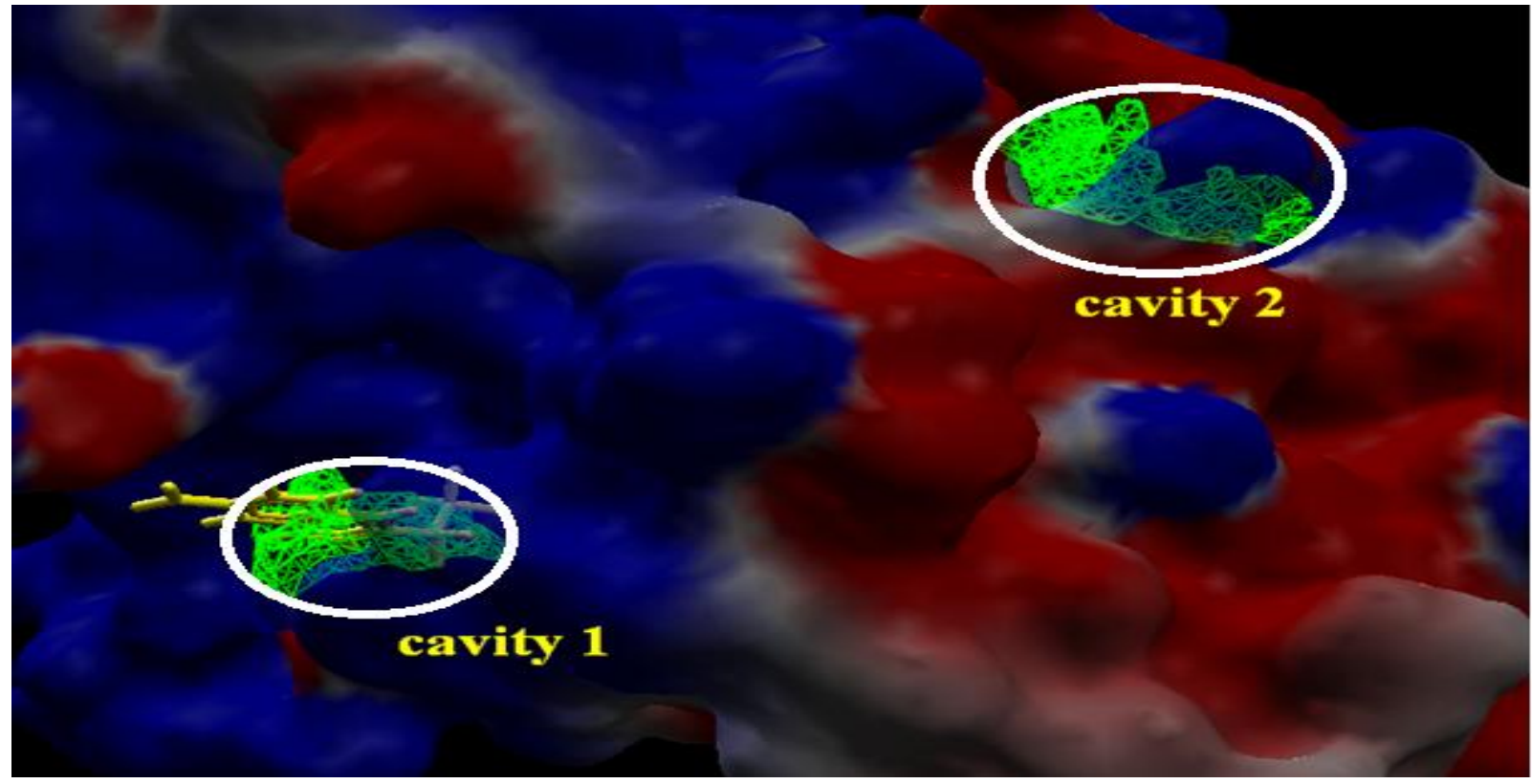

Fig2: Graphical interface with the cavities (cavity 1 and cavity 2 indicated by ellipses) identified by MolDock

\section{RESULTS AND DISCUSSION}

\subsection{Study of Ligand-Substrate Interaction}

$\mathrm{X}$-ray crystallographic study has previously performed to explain the enzyme-inhibitor interactions with PTP1B and benzofuran and benzothiophene biphenyls [37]. This work showed that PTP1B has two possible modes of binding at the active site depending on the structures of the ligands. Based on this result, molecular modeling was carried out to study the structural features of the interaction between PTP1B and six food dyes. Docking of these six food dyes were performed using MVD program. It was found that the residues in the site1(cavity1) as follows:Arg221, Ser216, Asp181, Phe182, Ala217, Val49, Asp48, Tyr46, Lys120, Gln262, Asp48, Ile219, Gly220, Cys215, Arg47, Glu262 and Lys116 are highly conserved within the active site. Also for the residues in the site2(cavity2) as follows: Lys248, Ala77, Glu252, Glu75, Leu234, Met75, Thr230, Val249, Glu76, Met74, Asp245, Phe256, Lys73, Val244, Gln78, Lys255, Leu251, Ser243, Arg238 are highly conserved within the active site. In this study, site 1 and site 2 are chosen as the binding site to dock with the food dyes diversity set molecules. 


\subsection{Virtual Screening}

The six ligands molecules having minimum energy were screened out as the possible inhibitors for PTPases (Table 3). In cavity1: All selected molecules were having energy MolDock score as follows: Ligand $\mathbf{L}_{\mathbf{1}}$ is having minimum energy MolDock score $-145.584 \mathrm{Kcal} / \mathrm{Mol}$. Ligand $\mathbf{L}_{2}$ is having - $138.408 \mathrm{Kcal} / \mathrm{Mol}$. Ligand $\mathbf{L}_{\mathbf{3}}$ is having -103.515 and Ligand $\mathbf{L}_{\mathbf{4}}$ is having energy MolDock score -137.544 $\mathrm{Kcal} / \mathrm{Mol}$. Ligand $\mathbf{L}_{\mathbf{5}}$ is having energy MolDock score147.036. Ligand $\mathbf{L}_{\mathbf{6}}$ is having energy MolDock score 113.958. With the help of the Ligplot+ study we have selected Ligand $\mathbf{L}_{\mathbf{5}}$ as the possible inhibitor lead molecule, as it has minimum energy MolDock score and one of the highest number of interactions with the active site residue, it has 07 hydrophobic and 09 hydrogen interactions. Figure 3 represent the binding modes of the different docking poses of the ligands were investigated on Ligplot+ program [38], according to the energy MolDock score in cavity1.
Also in cavity 2 : All selected molecules were having energy MolDock score as follows: Ligand $\mathbf{L}_{\mathbf{1}}$ is having minimum energy MolDock score $-141.283 \mathrm{Kcal} / \mathrm{Mol}$. Ligand $\mathbf{L}_{\mathbf{2}}$ is having $-106.417 \mathrm{Kcal} / \mathrm{Mol}$. Ligand $\mathbf{L}_{\mathbf{3}}$ is having -104.632 and Ligand $\mathbf{L}_{\mathbf{4}}$ is having energy MolDock score -101.029 $\mathrm{Kcal} / \mathrm{Mol}$. Ligand $\mathbf{L}_{\mathbf{5}}$ is having energy MolDock score115.254. Ligand $\mathbf{L}_{\mathbf{6}}$ is having energy MolDock score -95.455 . Also with the help of the Ligplot study we have selected Ligand $\mathbf{L}_{\mathbf{1}}$ as the possible inhibitor lead molecule, as it has minimum energy MolDock score and one of the highest number of interactions with the active site residue, it has 08 hydrophobic and 1 hydrogen interactions. Figure 4 represent interactions of the six ligands drawn by ligplot+ according to the energy MolDock score in cavity2.

Table 4(a,b): shows all hydrogen bonds and hydrophobic interactions exist between six ligands $\left(\mathbf{L}_{\mathbf{1 - 6}}\right)$ and active site(Cavity1 and Cavity2) respectively.

Table 3. Docking results of food dyes with PTP1B in the both cavities.

\begin{tabular}{|c|c|c|c|c|c|c|}
\hline & \multicolumn{3}{|c|}{ Cavity 1} & \multicolumn{3}{|c|}{ Cavity 2} \\
\hline & MolDockScore $^{\mathrm{a}}$ & Interaction $^{b}$ & H-bond & MolDock Score $^{\mathrm{a}}$ & Interaction $^{\mathbf{b}}$ & H-bond \\
\hline $\mathbf{L}_{1}$ & -145.584 & -152.31 & -15.564 & -141.283 & -134.772 & -8.481 \\
\hline $\mathbf{L}_{2}$ & -138.408 & -144.733 & -22.435 & -106.417 & -111.957 & -11.120 \\
\hline $\mathbf{L}_{3}$ & -103.515 & -101.218 & 0 & -104.632 & -114.957 & -2.383 \\
\hline $\mathbf{L}_{4}$ & -137.544 & -152.179 & -21.170 & -101.029 & -119.28 & -3.594 \\
\hline $\mathbf{L}_{5}$ & -147.037 & -157.729 & -23.253 & -115.254 & -118.117 & -8.451 \\
\hline $\mathbf{L}_{6}$ & -113.958 & -114.152 & -3.713 & -95.455 & -108.382 & -6.328 \\
\hline \multicolumn{4}{|c|}{$\begin{array}{l}\text { a MolDock score calculated by summing the external ligand } \\
\text { interaction (protein-ligand interaction) and internal ligand } \\
\text { interaction score using Virtual Molecular Viewer 1.2.0. }\end{array}$} & \multicolumn{3}{|c|}{$\begin{array}{l}{ }^{\mathbf{b}} \text { The total interaction energy between the pose and the tar } \\
\text { molecules(s). }\end{array}$} \\
\hline \multicolumn{7}{|c|}{$\begin{array}{l}\text { Table 4(a): List of amino acid residues involved in ligands-protein interaction between } L_{1-6} \text { and cavity1 as predicted by } \\
\text { Ligplot+ }\end{array}$} \\
\hline Compounds & & \multicolumn{2}{|c|}{ Hydrogen bond $(\leq 3.6 \AA)$} & \multicolumn{2}{|c|}{ Hydrophobic interactions } & \\
\hline $\mathbf{L}_{1}$ & & \multicolumn{2}{|l|}{$\operatorname{Arg} 221$} & \multicolumn{3}{|c|}{$\begin{array}{l}\text { Ser216, Asp181, Phe182, Ala217, Val49, Asp48, Tyr46, } \\
\text { Lys120. }\end{array}$} \\
\hline $\mathbf{L}_{2}$ & & \multicolumn{2}{|l|}{ Gln262, Asp48 } & \multicolumn{2}{|c|}{ Ile219, Val49, Ala217, Phe182. } & \\
\hline $\mathbf{L}_{3}$ & & \multicolumn{2}{|c|}{$\begin{array}{l}\text { Asp48, Ile219, Gly220, Cys215, } \\
\text { Arg221(2). }\end{array}$} & \multicolumn{3}{|c|}{ Arg47, Ala217, Glu262, Asp181, Phe182, Lys120, } \\
\hline $\mathbf{L}_{4}$ & & \multicolumn{2}{|c|}{$\begin{array}{l}\text { Arg221, Gly220, Lys116, } \\
\text { Asp181(2), Lys120(2), Phe182 }\end{array}$} & \multicolumn{3}{|c|}{ Cys215, Gln262, Ala217, Ile219, Tyr46. } \\
\hline $\mathbf{L}_{\mathbf{5}}$ & & \multicolumn{2}{|c|}{$\begin{array}{l}\text { Asp48, Gln262(3), Cys215, } \\
\text { Gly220, Arg221(2),Phe182 }\end{array}$} & \multicolumn{3}{|c|}{ Val49, Tyr46, Ala217, Ile219, Ser216, Ser216, Asp181. } \\
\hline $\mathbf{L}_{6}$ & & \multicolumn{2}{|c|}{$\begin{array}{l}\text { Phe182, Gly220,Lys 120(2), } \\
\text { Cys215, Arg221(2) }\end{array}$} & \multicolumn{3}{|c|}{ Gln262, Ala217, Tyr46, Val49, Ser216, Asp181. } \\
\hline
\end{tabular}


Table 4(b): List of amino acid residues involved in ligands-protein interaction between $L_{1-6}$ and cavity2 as predicted by Ligplot+

\begin{tabular}{lll}
\hline Compounds & Hydrogen bond $\mathbf{(} \leq \mathbf{3 . 6} \mathbf{A})$ & Hydrophobic interactions \\
\hline & & \\
$\mathbf{L}_{\mathbf{1}}$ & Lys248 & Ala77, Glu252, Glu75, Leu234, Met75, Thr230, \\
& & Val249, Glu76 \\
$\mathbf{L}_{\mathbf{2}}$ & Glu75, Ala77, Lys248 & Glu252, Met74, Val249, Glu76 \\
$\mathbf{L}_{\mathbf{3}}$ & Glu76, Asp245 & Phe256, Lys73, Met74, Glu75, Ala77, Thr230, \\
$\mathbf{L}_{\mathbf{4}}$ & Glu76, Glu75 & Leu234, Lys248, Val244, Val249, Glu252 \\
& Val249, Leu234, Met74, Gln78, Lys248, Glu252 \\
$\mathbf{L}_{\mathbf{5}}$ & Lys255, Ala77, Glu75 & Lys248, Glu252, Glu76, Leu251, Phe256, Lys73, \\
$\mathbf{L}_{\mathbf{6}}$ & Glu252, Asp245, Ser243, Arg238 & $\begin{array}{l}\text { Met7475, Glu76, Met74, Ala77, Leu234, Val249, } \\
\text { Lys248, Val244 }\end{array}$ \\
\hline
\end{tabular}



$\mathbf{L}_{1}$

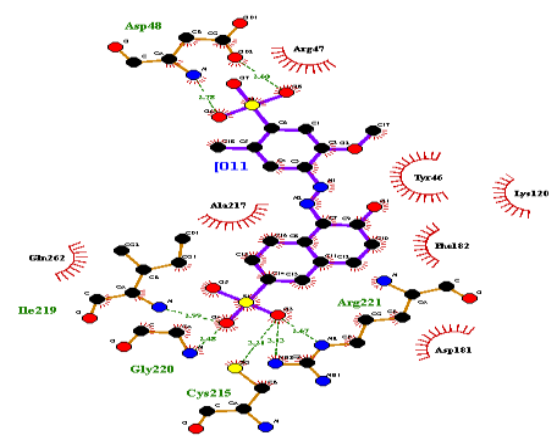

$\mathbf{L}_{3}$

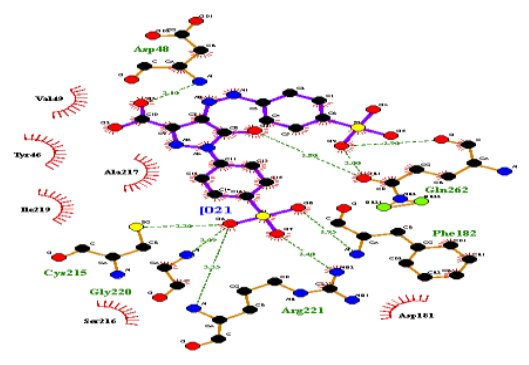

$\mathbf{L}_{5}$

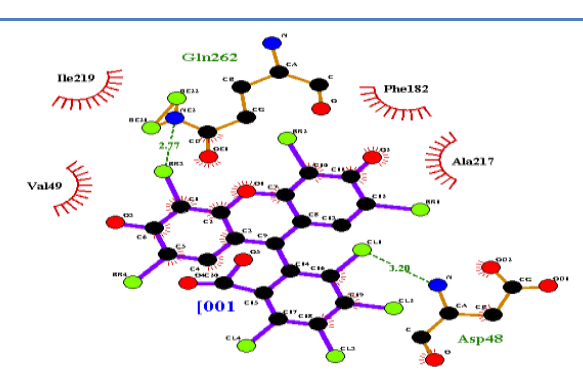

$\mathbf{L}_{2}$

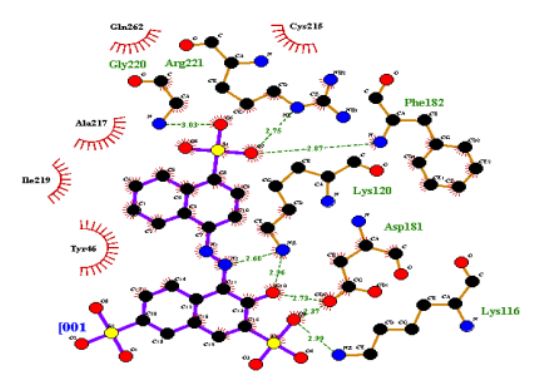

$\mathbf{L}_{4}$



$\mathbf{L}_{6}$

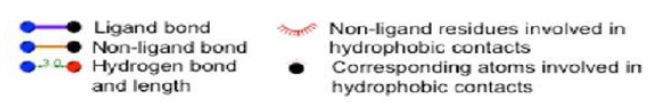

Fig 3: the protein-ligand interactions of six ligands in cavity1, based on energy MolDock score (hydrogen bonding and hydrophobic), generated by Ligplot+ program. $\mathrm{L}_{1}$ : Erythrosine B, $\mathrm{L}_{2}$ : Phloxine B, $\mathrm{L}_{3}$ : Allura Red AC, $\mathrm{L}_{4}$ : Amaranth, $\mathrm{L}_{5}$ : Tartrazine $\mathrm{L}_{6}$ : Sunset Yellow FCF 


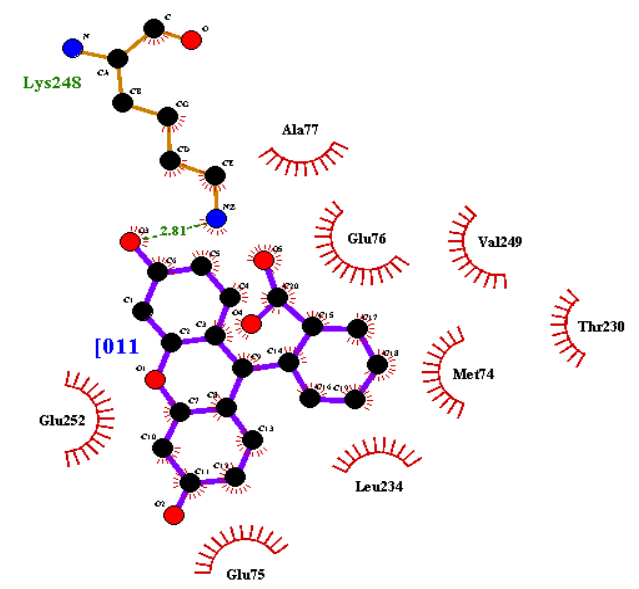

$\mathbf{L}_{1}$

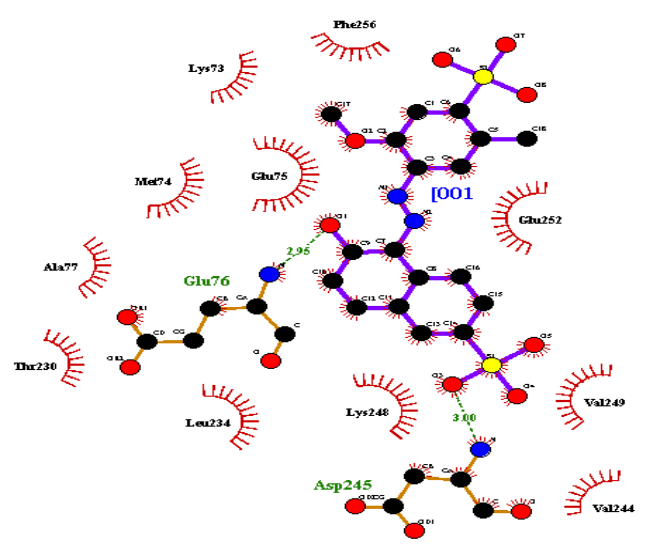

$\mathbf{L}_{3}$

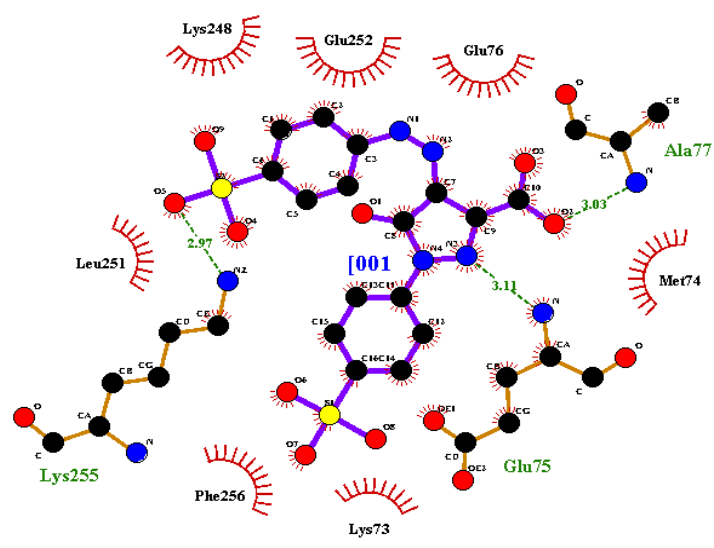

$\mathbf{L}_{5}$

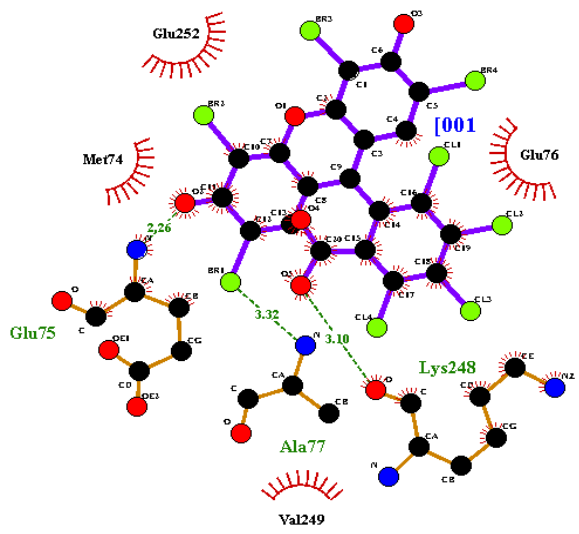

$\mathbf{L}_{2}$

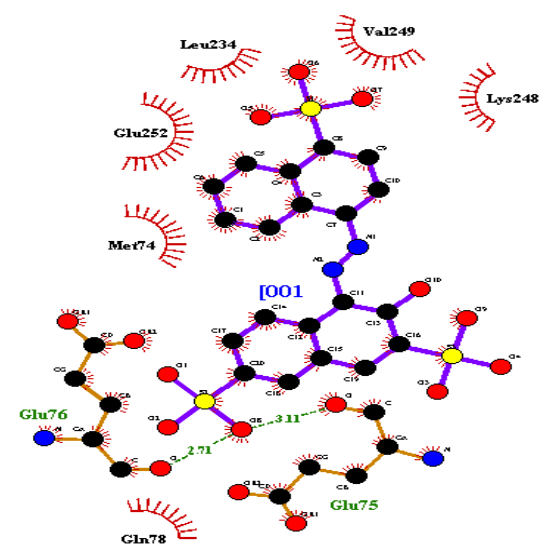

$\mathbf{L}_{4}$

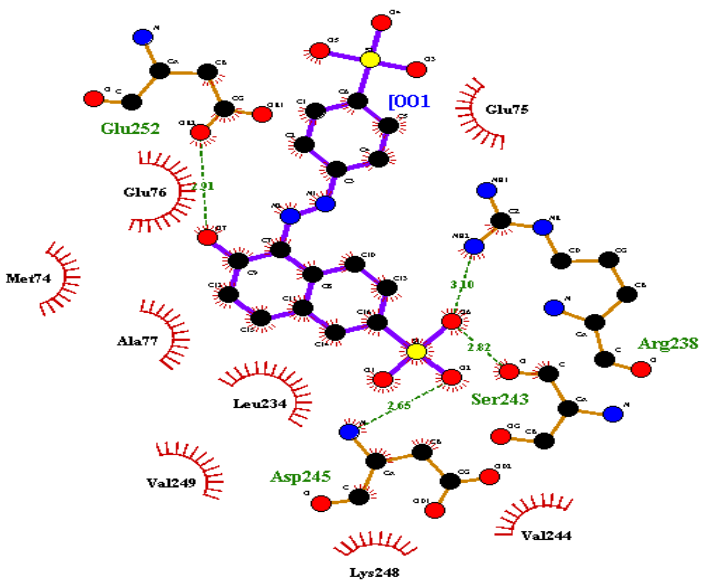

$\mathbf{L}_{6}$

Fig 4: the protein-ligand interactions of six ligands in cavity2, based on energy MolDock score (hydrogen bonding and hydrophobic), generated by Ligplot+ program. $L_{1}$ : Erythrosine B, $L_{2}$ : Phloxine B, $L_{3}$ : Allura Red AC, $L_{4}$ : Amaranth, $L_{5}$ : Tartrazine $\mathrm{L}_{6}$ : Sunset Yellow FCF

According to the results obtained by molecular docking, result of cavity 2 has agreement with experimental study [19] and detailed binding pattern of an inhibitor $\mathbf{L}_{\mathbf{1}}$ exhibiting the second lowest $\mathrm{IC}_{50}$ is shown in Table 2 . $\mathbf{L}_{\mathbf{1}}$ extended deep into the active site pocket, making several hydrogen bonds and hydrophobic interactions with key residues of the catalytic site. One carboxyl group of $\mathbf{L}_{\mathbf{1}}$ forms one hydrogen bonds with Lys248 and Ala77, Glu252, Glu75, Leu234, Met75, 
Thr230, Val249, Glu76 forms hydrophobic interactions with $\mathbf{L}_{1}$ (Table 4(b)).

\section{CONCLUSION}

The molecular docking analysis resulted in the identification of potential ligands $\left(\mathbf{L}_{\mathbf{1 - 6}}\right)$ molecules. Hence, in present study, it can be concluded that molecules $\mathbf{L}_{\mathbf{5}}$ and $\mathbf{L}_{\mathbf{1}}$ in cavity 1 and 2 respectively have the potential to inhibit the activity of PTP1B and can might cause harmful effects in human health. $\mathbf{L}_{\mathbf{5}}$ and $\mathbf{L}_{\mathbf{1}}$ does not only show interactions with identified active residues that are important for catalytic activity of PTP1B but the free energy of binding also ensures that $\mathbf{L}_{5}$ and $\mathbf{L}_{\mathbf{1}}$ shows a very strong binding with PTP1B at polymerase active site.

\section{ACKNOWLEDGMENTS}

Our thanks to the experts who have contributed towards development of the template.

\section{REFERENCES}

[1] Zhan X. L, Wishart M. J. and Guan K. L. 2001. Nonreceptor tyrosine phosphatases in cellular signaling: regulation of mitogen-activated protein kinases. Chem. Rev; 101(8), 2477-96.

[2] Östman A. and Böhmer F. D. 2001. Regulation of receptor tyrosine kinase signaling by protein tyrosine phosphatases. Trends. Cell. Biol; 11(6), 258-66.

[3] Cohen P. 2000. The regulation of protein function by multisite phosphorylation-A 25 year update. Trends. Biochem. Sci ; 25(12), 596-601.

[4] Neel B. G. and Tonks N. K. 1997. Protein tyrosine phosphatases in signal transduction. Curr. Opin. Cell. Biol; 9(2), 193-204.

[5] Zhang Z. Y. 2002. Protein tyrosine phosphatases: structure and function, substrate specificity, and inhibitor developmen. Annu. Rev. Pharmacol. Toxicol; 42(1), 209-243.

[6] Denu J. M. and Dixon J. E. 1998. Protein tyrosine phosphatases: mechanisms of catalysis and regulation. Curr. Opin. Chem. Biol; 2(5), 633-641.

[7] Hunter T. and Sefton B. M. 1980. Transforming gene product of Rous sarcoma virus phosphorylates tyrosine. Proc. Natl. Acad. Sci; 77(3), 1311-1315.

[8] Tonks N. K, Diltz C. D. and Fischer E. H. 1988. Purification of the major protein tyrosine-phosphatases of human placenta. J. Biol. Chem; 263(3), 6722-6730.

[9] Tonks N. K, Diltz C. D. and Fischer E. H. 1988. Characterization of the major protein tyrosinephosphatases of human placenta. J. Biol. Chem; 263(14), 6731-6737.

[10] Blaskovich M. A. and Kim H. O. 2002. Recent discovery and development of protein tyrosine phosphatase inhibitors. Exp. Opin. Ther. Pat; 12(6), 871-905.

[11] Charbonneau H, Tonks N. K, Walsh K. A. and Fischer E. H. 1988. The leukocyte common antigen (CD45): a putative receptor-linked protein tyrosine phosphatase. Proc. Natl. Acad. Sci; 85(19), 7182-7186.

[12] Goldstein B. 1998. Tyrosine Phosphoprotein Phosphatases (2nd ed.)Oxford: Oxford University Press.
[13] Revankar S. M. and Lel, S. S. 2007. Synthetic dye decolorization by white rot fungus, Ganoderma sp. WR1. Bioresour. Technol; 98(4), 775-780.

[14] Downham A. and Collins P. 2000. Coloring our foods in the last and next millennium. Int. J. Food. Sci. Technol ; $35(1), 5-22$

[15] Minioti S. K, Sakellariou F. C. and Thomaidis S. N. 2007. Determination of 13 synthetic food colorants in water-soluble foods by reversed-phase high performance liquid chromatography coupled with diode-array detector. Anal. Chim. Acta; 583(1), 103-110.

[16]Shrestha S, Shim Y. S. Kim K. C, Lee K. H. and Cho H. 2004. Evans Blue and other dyes as protein tyrosine phosphatase inhibitors. Bioorg. Med. Chem. Lett; 14(8), 1923-1926.

[17] Cho H, Lee D. Y, Shrestha S, Shim Y. S, Kim K. C, Kim M. K, Lee K. H, Won J. and Kang J. S. 2004. Aurintricarboxylic acid translocates across the plasma membrane, inhibits protein tyrosine phosphatase and prevents apoptosis in PC12 cells. Mol. Cells; 18(1), 4652.

[18] Neel B. G. and Tonks N. K. 1997. Protein tyrosine phosphatases in signal transduction. Curr. Opin. Cell. Biol; 9(2), 193-204.

[19] Shrestha S, Bhattarai B. R, Lee K. H. and Cho H. 2006. Some of the Food Color Additives Are Potent Inhibitors of Human Protein Tyrosine Phosphatases. Bull. Korean. Chem. Soc; 27(10), 1567-1571.

[20] Stewart J. J. P. 2007. Optimization of parameters for semi-empirical methods V: modification of NDDO approximations and application to 70 elements. J. Mol. Model; 13(12), 1173-1183.

[21] Labanowski J. K. and Andzelm J. W. 1991. Editors. Density functional methods in chemistry. New York: Springer Verlag; p.443.

[22] Baker J. 1986. An algorithm for the location of transition states. J. Comput. Chem; 7(4), 385-395.

[23] Schlegel H. B. 1994. editor. Modern electronic structure theory: geometry optimization on potential energy surfaces. Singapore: World Scientific.

[24] Hehre W. J, Radom L, Schleyer P. V. R. and Pople J. A. 1986. Ab initio molecular orbital theory. New York: Wiley.

[25] Hariharan P. C. and Pople J. A. 1973. The influence of polarization functions on molecular orbital hydrogenation energies. Theor. Chim. Acta; 28(3), 213 235 .

[26] Becke AD. 1988. Density-functional exchange-energy approximation with correct asymptotic behavior. Phys. Rev A; 38(6), 3098-3100.

[27] Becke A. D. 1993. A new mixing of HartreeeFock and local density-functional theories. J. Chem. Phys; 98(3), 1372-1381.

[28] Lee C, Yang W. and Parr R. G. 1988. Development of the Colle-Salvetti correlation-energy formula into a functional of the electron density. Phys. Rev B; 37(4),785-794. 
[29] Frisch M. J, Trucks G. W, Schlegel H. B, Scuseria G. E, Robb M. A. and Cheeseman J. R, et al. 2004. Gaussian 03, Revision D.01. Wallingford, CT: Gaussian, Inc.

[30] Groves M. R, Yao Z. J, Roller P. P, Burke J. T. R. and Barford D. 1998. Structural basis for inhibition of the protein tyrosine phosphatase 1B by phosphotyrosine peptide mimetics. Biochemistry; 37(51), 17773-17783.

[31] Berman H. M, Westbrook J, Feng Z, Gilliland G, Bhat T. N, Weissig H, Shindyalov I. N. and Bourne P. E. 2000. The Protein Data Bank. Nucleic. Acids. Res; 28(1), 235242.

[32] da Cunha E. F. F, Martins R. C. A. and Albuquerque M. G. 2004. LIV-3D-QSAR model for estrogen receptor ligands. J. Mol. Mod; 10(5), 297-304.

[33] Elaine F. F, da Edilaine F. B, Aline A. O. and Teodorico C. R. 2010. Molecular modeling of Mycobacterium tuberculosis DNA gyrase and its molecular docking study with gatifloxacin inhibitors. J. Biom. Struct. Dyn; 27(5), 619-625.
[34] Ramalho T. C, Rocha M. V. J, da Cunha E. F. F. and Freitas M. P. 2009. The search for new COX-2 inhibitors. Expert. Opin. Ther. Pat; 19(9), 1193-1228.

[35] Thomsen R. and Christensen M. H. 2006. MolDock: a new technique for highaccuracy molecular docking. J. Med. Chem; 49(11), 3315-3321.

[36] Schulz H, Dale E, Karimi-Nejad Y. and Oefner C. 2009. Structure of human endothe-linonverting enzyme I complexed with phosphoramidon. J. Mol. Biol; 385(1), 178-187.

[37] Malamas M. S, Sredy J, Moxham C, Katz A, Xu W, McDevitt R, Adebayo F. O, Sawicki, D. R, Seestaller L, Sullivan D. and Taylor JR. 2000. J. Med. Chem; 43: 1293.

[38] Wallace, A. C. Laskowski, R. A. and Thornton, J. M. 1995. LIGPLOT: a program to generate schematic diagrams of protein-ligand interactions. Protein. Eng., 8, $127-134$. 